\title{
Molecular mechanism by which acyclic retinoid induces nuclear localization of transglutaminase 2 in human hepatocellular carcinoma cells
}

\author{
R Shrestha ${ }^{1,2}$, H Tatsukawa ${ }^{3}$, R Shrestha ${ }^{1,4}$, N Ishibashi ${ }^{5}$, T Matsuura ${ }^{6}$, H Kagechika ${ }^{2}$, S Kose ${ }^{7}$, K Hitomi $^{3}$, N Imamoto ${ }^{7}$ and S Kojima ${ }^{\star, 1,2,4}$
}

Nuclear accumulation of transglutaminase 2 (TG2) is an important step in TG2-dependent cell death. However, the underlying molecular mechanisms for nuclear translocation of TG2 are still poorly understood. In this study, we demonstrated that acyclic retinoid (ACR) induced nuclear accumulation of TG2 in JHH-7 cells, a hepatocellular carcinoma (HCC) leading to their apoptosis. We further demonstrated molecular mechanism in nuclear-cytoplasmic trafficking of TG2 and an effect of ACR on it. We identified a novel 14-amino acid nuclear localization signal (NLS) ${ }^{466}$ AEKEETGMAMRIRV ${ }^{479}$ in the 'C' domain and a leucine-rich nuclear export signal (NES) ${ }^{657}$ LHMGLHKL ${ }^{664}$ in the 'D' domain that allowed TG2 to shuttle between the nuclear and cytosolic milieu. Increased nuclear import of GAPDH myc-HIS fused with the identified NLS was observed, confirming its nuclear import ability. Leptomycin B, an inhibitor of exportin-1 as well as point mutation of all leucine residues to glutamine residues in the NES of TG2 demolished its nuclear export. TG2 formed a trimeric complex with importin- $\alpha$ and importin- $\beta$ independently from transamidase activity which strongly suggested the involvement of a NLS-based translocation of TG2 to the nucleus. ACR accelerated the formation of the trimeric complex and that may be at least in part responsible for enhanced nuclear localization of TG2 in HCC cells treated with ACR.

Cell Death and Disease (2015) 6, e2002; doi:10.1038/cddis.2015.339; published online 3 December 2015

Transglutaminase 2 (TG2) is a multifunctional enzyme and the primary member of a family of $\mathrm{Ca}^{2+}$-dependent crosslinking enzymes that catalyze posttranslational modification of proteins to form $\mathrm{N}^{\varepsilon}\left(\gamma\right.$-glutamyl) lysine bonds. ${ }^{1}$ Structurally TG2 is composed of four domains: an $\mathrm{NH}_{2}$-terminal $\beta$ sandwich domain; a catalytic core domain containing a catalytic triad for the acyl-transfer reaction (Cys277, His335 and Asp358) for acyl-transfer reaction; a $\beta$-barrel ${ }_{1}$ domain, containing GDP/GTP-interacting residues, that is involved in receptor signaling and a $\beta$-barrel ${ }_{2}$ domain. ${ }^{1}$ Two conformational arrangements of the four domains in TG2 have been resolved. In the GTP/GDP-bound TG2, the two $\mathrm{COOH}$ terminal $\beta$-barrel domains are folded into the core domain rendering TG2 in a 'closed' conformation covering the transamidation catalytic site. ${ }^{2}$ Similar structure was reported for ATP-bound TG2. ${ }^{3}$ On the contrary, the two C-terminal domains moved further apart aligning the four domains to make up an extended 'open' conformation in a pentapeptide TG2 inhibitor, Ac-P(DON)LPF-NH ${ }_{2}$-bound TG2 complex ${ }^{4}$ and in the presence of $\mathrm{Ca}^{2+}$ exposing the catalytic site. ${ }^{5,6}$

One of the features of the TG2 is the reciprocal regulation of the enzyme to act as a G protein in 'closed' form or as a transamidation enzyme in 'open' form. In as low intracellular
$\mathrm{Ca}^{2+}$ concentrations as $10 \mathrm{nM}$, it mainly acts as a GTPasesupporting growth. ${ }^{7-9}$ In contrast, when cells are injured and the intracellular $\mathrm{Ca}^{2+}$ concentration exceeds $700-800 \mathrm{nM}$, it acts as a crosslinking enzyme suppressing cell growth and inducing apoptosis. ${ }^{9,10}$ Another feature of TG2 is cellular distribution of the enzyme. While it is predominantly found in cytoplasm, it is also distributed in extracellular matrix and in various subcellular locations including plasma membrane, mitochondria, recycling endosomes and nucleus. ${ }^{11}$ Depending on in which milieu and what biological activity TG2 exerts, cell growth, differentiation and apoptosis are variously regulated. ${ }^{8,12-14}$

Acyclic retinoid (ACR), a synthetic retinoid prevents the recurrence and development of $\mathrm{HCC}$ in patients after surgical removal of the primary tumors by inducing apoptosis. ${ }^{15,16}$ Retinoid X receptor (RXR) $a$ is highly phosphorylated and loses its activity as a transcriptional factor during carcinogenesis in HCC. ${ }^{17}$ ACR prevents this aberrant hyper-phosphorylation of (RXR) $a$ by suppressing the Ras-extracellular signal regulated kinase (Erk) pathway, thereby restoring (RXR) a's activity in response to physiological concentrations of 9-cis retinoic acid. ${ }^{18}$ A novel TG2-dependent apoptotic pathway is also involved in the apoptosis of HCC cells treated with ACR. ${ }^{19} \mathrm{ACR}$ stimulates the expression, nuclear localization and crosslinking

\footnotetext{
${ }^{1}$ Micro-Signaling Regulation Technology Unit, Division of Bio-Function Dynamics Imaging, RIKEN Center for Life Science Technologies, Wako, Saitama, Japan; ${ }^{2}$ Graduate School of Medical \& Dental Sciences, Tokyo Medical and Dental University, Bunkyo-ku, Tokyo, Japan; ${ }^{3}$ Department of Basic Medicinal Science, Graduate School of Pharmaceutical Sciences, Nagoya University, Furo-cho, Chikusa Nagoya, Aichi, Japan; ${ }^{4}$ Graduate School of Bioscience and Biotechnology, Department of Life Science, Tokyo Institute of Technology, Yokohama, Kanagawa, Japan; ${ }^{5}$ Tokyo New Drug Research Laboratories, Pharmaceutical Division, KOWA Company, Ltd., Higashimurayama, Tokyo, Japan; ${ }^{6}$ Department of Laboratory Medicine, The Jikei University School of Medicine, Nishi-shinbashi, Minato-ku, Tokyo, Japan and ${ }^{7}$ Cellular Dynamics Laboratory, RIKEN, Wako, Saitama, Japan

*Corresponding author: S Kojima, Micro-Signaling Regulation Technology Unit, RIKEN Center for Life Science Technologies, 2-1 Hirosawa, Wako, Saitama 351-0198, Japan. Tel: +81 48467 7938; Fax: +81 48462 4675; E-mail: skojima@ riken.jp

Abbreviations: ACR, acyclic retinoid; TG2, transglutaminase 2; HCC, hepatocellular carcinoma; NLS, nuclear localizing signal; NES, nuclear export signal; RXR, retinoid $X$ receptor; EtOH, ethanol; LMB, leptomycin B; GST, glutathione S-transferase

Received 10.6.15; revised 20.10.15; accepted 21.10.15; Edited by E Candi
} 


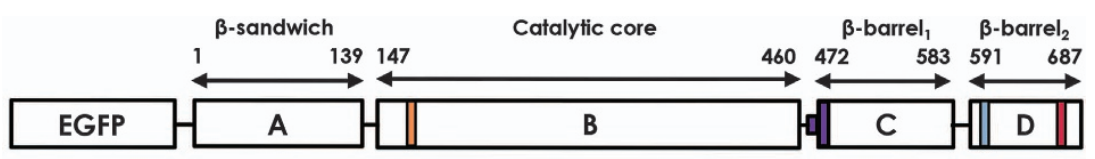

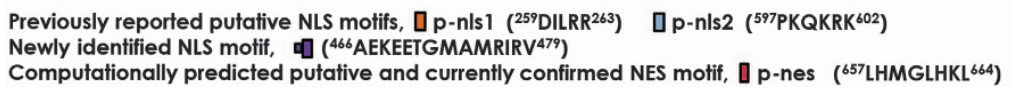

Figure 1 Domain structure of human TG2. Schematic diagram of EGFP-tagged human TG2 showing its four structural domains (a-d), previously reported two putative NLSs (p-nls1 and p-nls2), newly identified NLS, and computationally predicted putative and currently confirmed NES (p-nes)

activity of TG2, resulting in crosslinking and inactivation of a transcription factor, Sp1, thereby reducing expression of epidermal growth factor receptor and inducing cell death in HCC. $^{19}$ This novel TG2-dependent apoptotic pathway is also involved in alcoholic and nonalcoholic liver injuries. ${ }^{20-22}$ The nuclear abundance of TG2 appears to be particularly relevant, as this has been previously found to be associated with apoptosis in other cell types. ${ }^{1,8,23-26}$ Therefore, nuclear accumulation of TG2 is of importance to regulate TG2-dependent cell death. However, its molecular mechanism is largely unknown.

Nuclear transport is a highly regulated process that dictates whether a cargo can enter into and exits from the nucleus. ${ }^{27} \mathrm{~A}$ variety of nuclear transport pathways occur in human cells that are mediated by different carrier molecules, each of which transports a specific range of macromolecules into or out of the nucleus. ${ }^{27-29}$ Human genome encodes at least 20 members of the importin- $\beta$ family that mediates the nucleocytoplasmic transport of most proteins and RNAs. ${ }^{28}$ Most of importin- $\beta$ family members, interact with nuclear localization signal (NLS) and nuclear export signal (NES) directly and translocate the containing cargoes. For importin- $\beta 1$, in addition to the direct interaction, it utilizes importin- $a$ family proteins as adaptors to bind with NLS, and mediates nuclear import of many different proteins. ${ }^{28,29}$ Importin- $a$ family proteins are grouped into three major subfamilies (a) importin-a1/Rch1/KPNA2, (b) importin-a3/Qip1/KPNA4, importin- $a 4 / \mathrm{SRP} 1 \gamma / \mathrm{KPNA3}$ and (c) importin-a5/NPI1/KPNA1, importin- $a 6 /$ KPNA5 and importin- $a 7 /$ KPNA6. The members of inter subfamilies share about $50 \%$ of sequence identity while it is at least $80 \%$ for intra subfamilies. ${ }^{30}$

Based on primary sequence analysis, Peng et al., ${ }^{31}$ suggested that TG2 contains computationally predicted putative bipartite NLSs located at positions ${ }^{259}$ DILRR $^{263}$ termed here as p-nls1 and ${ }^{597}$ PKQKRK ${ }^{602}$ termed here as p-nls2, as shown in Figure 1 with high homology to NLS of NS1 nonstructural protein of influenza virus. ${ }^{31,32}$ They also showed that a nuclear transport factor, importin- $\alpha 3$, as a binding partner of TG2 by using yeast two-hybrid system, is involved in translocation of TG2 to the nucleus. They also confirmed the interaction of importin- $\alpha 3$ with TG2 in non-small cell lung cancer cell lines by immunoprecipitation. However, no additional mechanistic details have been identified. We previously showed that ethanol (EtOH) enhances messenger RNA expression of both TG2 and importin- $\alpha 3$ increasing nuclear TG2 in hepatic cells. ${ }^{20}$ TG2 also contains a computationally predicted putative leucine-rich NES at the position ${ }^{657}$ LHMGLHKL $^{664}$, near the C terminus. ${ }^{33,34}$ This is one of the generally accepted consensus NES motif ( $\operatorname{xxxLxxL)}$ critical for exportin-1 binding, regulating the export of proteins from the nucleus to the cytoplasm in several organisms. ${ }^{33,35-37}$

A critical step controlling the TG2-dependent apoptotic pathway is nuclear localization of TG2. However, underlying molecular mechanisms of TG2 translocation from cytoplasm to nucleus still remains unclear. In this study, we found that TG2 transported into the nucleus via a novel 14-amino acid NLS located within the third domain of TG2 forming a trimeric complex 'TG2/importin-a/importin- $\beta$ ', while it shuttled back to cytoplasm via a leucine-rich NES region near $C$ terminus of TG2. The formation of the trimeric complexes was promoted by ACR, at least in part through which it enhanced the nuclear accumulation of TG2 in a $\mathrm{HCC}$ cell line, $\mathrm{JHH}-7$ cells leading to apoptosis.

\section{Results}

ACR-induced accumulation of TG2 in the nucleus of HCC cells, leading to their cell death. Monitoring by time lapse of JHH-7 cells overexpressing EGFP-TG2 showed four types of cells on treatment with EtOH (control) and ACR in the presence or absence of R283, (a site-directed TG inhibitor) ${ }^{13}$ and Z-DON (a specific TG2 inhibitor) ${ }^{38}$ for $12 \mathrm{~h}$, including (1) the cells that had expressed cytosolic TG2 and died, (2) the cells that had expressed cytosolic TG2 and remained alive, (3) the cells that had expressed nuclear TG2 and died and (4) the cells that had expressed nuclear TG2 and remained alive (Figure 2a). Numbers of these four types of cells in $320 \mu \mathrm{m}^{2}$ area were counted under the indicated three conditions and percentages of cells in each category against total number of cells in these four categories were calculated and plotted. The cells treated with $0.1 \% \mathrm{EtOH}$ expressed EGFP-TG2 in the cytosol only and were in the categories 1 and $2(25 \%$ of the cells were dead (category 1 ), while $75 \%$ of the cells were alive (category 2)). In contrast, in cells treated with $10 \mu \mathrm{M}$ ACR, percentage of the alive cells overexpressing cytosolic EGFP-TG2 decreased from 75 to $23 \%$ (category 2) and instead $41 \%$ of the cells were in the categories 3 and $4(25 \%$ were dead (category 3 ) and $16 \%$ were alive (category 4)). They started to express nuclear TG2 4-6 h after treatment and underwent apoptosis (Figures $2 \mathrm{a}$ and $2 \mathrm{~b}$ ) with membrane blebbing, shrinkage 6-10 h after treatment (Figures $2 \mathrm{~b}$ and c). These results suggested that ACR induces first nuclear accumulation of TG2 and then causes apoptosis in $\mathrm{JHH}-7$ cells. To confirm the role of TG2 activity in cell death, we treated the cells with ACR in presence of $100 \mu \mathrm{M}$ R283 and $50 \mu \mathrm{M}$ Z-DON. We observed that the number of cells undergoing apoptosis after nuclear expression of TG2 

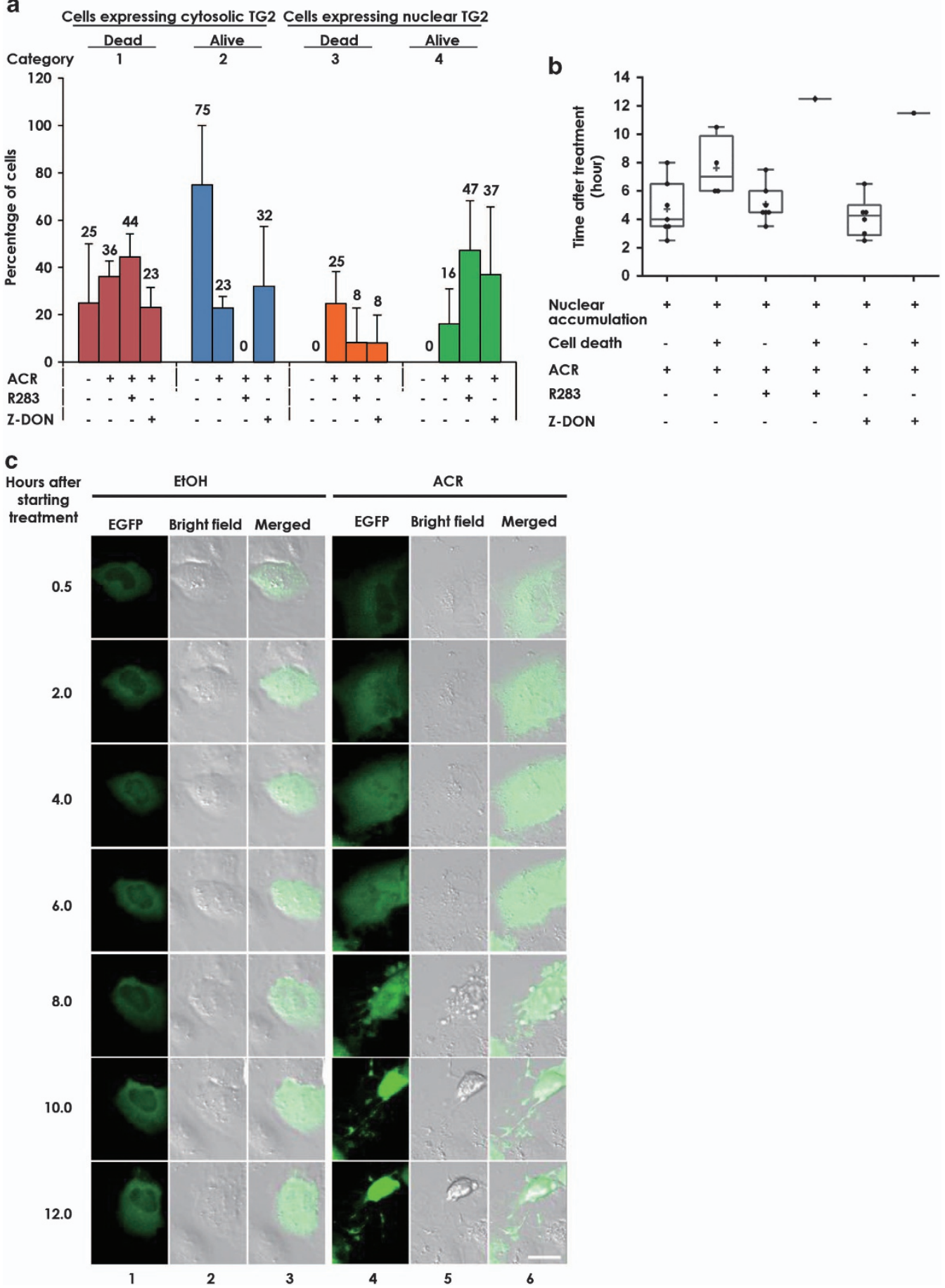

Figure 2 Time lapse observation of intracellular distribution of overexpressed recombinant human TG2 and cell fate in ACR-treated JHH-7 cells. JHH-7 cells were seeded at $2 \times 10^{5}$ cells per $35 \mathrm{~mm}$ glass based dish coated with Type-I C collagen. The cells were transiently transfected with $0.8 \mu \mathrm{g}$ of TG2-pEGFP-C1. Six hours after, the cells were treated with either vehicle $(0.1 \% \mathrm{EtOH})$ or $10 \mu \mathrm{M} \mathrm{ACR} \pm 100 \mu \mathrm{M}$ R283 or $50 \mu \mathrm{M}$ Z-DON. The transfected cells that expressed exogenously overexpressed TG2 (as judged by EGFP fluorescence intensity) at similar extent were monitored under time lapse for the next $12 \mathrm{~h}$ (a) Change in numbers of cells having the different cellular distribution of the overexpressed TG2 categorized as cytoplasmic or nuclear, and cell fate as dead or alive. Number of cells in each category out of total number of cells are expressed in percentages and plotted as bar graphs. Hundred percent represents sum of the number of cells in four categories under observation expressing exogenous EGFP-tagged TG2. Quantitated data presented as mean \pm S.D. of three independent experiments $(n=3-7)$. (b) Time course changes in each category of ACR-treated cells are plotted as box and whisker diagrams showing each sample value as a dot. The lower side and upper side of boxes represent 25 and 75 percentiles in each distribution, respectively. The line and plus sign inside the box represents median and mean value, respectively. Ends of the whiskers represent either the highest or lowest sample values. (c) Changes in intracellular distribution of overexpressed TG2 and in the cells and their morphology monitored by the time lapse. A representative single cell treated with either $0.1 \% \mathrm{EtOH}$ (left-hand side three columns) or $10 \mu \mathrm{M} \mathrm{ACR}$ (right-hand side three columns) showing cell fate at the indicated time points after starting the treatment is presented. A scale bar, $20 \mu \mathrm{m}$. A representative result from three independent experiments with similar results is presented 
decreased from 25 to $8 \%$ (category 3 ) in R283- and Z-DONtreated cells, while the number of living cells overexpressing the nuclear TG2 increased from 16 to $47 \%$ and $37 \%$, respectively, in R283- and Z-DON-treated cells (Figure 2a). These data were consistent with the previous work demonstrating an importance of transamidase activity in a TG2mediated cell death process. ${ }^{19,39}$ Nuclear TG2-dependent apoptosis is usually accompanied by caspase-3-dependent cascade pathway. ${ }^{19}$ Actually the cells treated with $10 \mu \mathrm{M} \mathrm{ACR}$ showed 1.3-, 1.5- and 3-folds higher levels of the activated caspase-3 than EtOH-treated control cells at 4, 8 and $12 \mathrm{~h}$ of treatment. Inclusion of a caspase-3 inhibitor zDEVD partially prevented ACR-induced apoptosis (Supplementary Figure 1) as reported before. ${ }^{19}$

The ' $C$ ' domain of TG2 played an important role in nuclear accumulation of TG2 and had a promising NLS sequence. We made several constructs for recombinant human TG2 domain(s)-deleted mutants tagged with EGFP at $\mathrm{N}$-terminal side (Figure $3 \mathrm{a}$ ). $\mathrm{JHH}-7$ cells were transfected with these constructs whose intracellular distributions were observed in the presence and absence of ACR under a confocal microscopy. TG2 (ABC); aa1-586 that lacked 'D' domain of TG2 thereby not containing the p-nls2 (putative NLS sequence computationally predicted in the previous paper, ${ }^{31}$ see Figure 1) showed nuclear localization regardless of ACR treatment (Figure 3b, row 3), while TG2 (AB); aa1-465, which lacked both ' $C$ ' and ' $D$ ' domains, did not localize to the nucleus even after treatment with ACR (Figure 3b, row 4). In contrast, TG2 (C); aa466-586 translocated to the nucleus regardless of ACR treatment (Figure 3b, row 5). Quantitative representations for the images in Figure $3 \mathrm{~b}$ are shown in Supplementary Figure 2A.

Subsequently, we found that 'AB' domain extended to the initial N-terminal 14-amino acid fragment of ' $C$ ' domain at position ${ }^{466}$ AEKEETGMAMRIRV ${ }^{479}$ (Figure 3c, row 2 ), as well as this 14-amino acid fragment alone (Figure 3c, row 3 ) translocated to the nucleus. To verify if this novel 14-amino acid motif showed ability as NLS, chimeric recombinant human GAPDH proteins, which were fused either with SV40 NLS (PKKKRKV) or with ${ }^{466}$ AEKEETGMAMRIRV ${ }^{479}$ at $\mathrm{N}$ terminus and with myc-HIS at $\mathrm{C}$ terminus, were examined for their subcellular localization when overexpressed in $\mathrm{JHH}-7$ cells (Figure $3 d$ ). The wild-type GAPDH-myc-HIS protein was found predominantly in the cytoplasm (Figure 3d, row 1); while the TG2 ' $C$ ' domain 14 amino acid-fused GAPDH translocated in the nucleus (Figure 3d, row 3) like SV40 NLS-fused GAPDH (Figure 3d, row 2). Quantitative representations for the images in Figure 3d are shown in Supplementary Figure 2B.

A promising role of TG2 ' $D$ ' domain in nuclear export of TG2. TG2 (CD); aa466-687 was constructed and overexpressed in $\mathrm{JHH}-7$ cells. The addition of ' $\mathrm{D}$ ' domain (aa587-687) to TG2 (C) sustained its accumulation in the nucleus following treatment with ACR (Figure 4a, row 2 righthand side two panels). However, in contrast to TG2 (C) alone, this mutant did not show nuclear localization in untreated cells (Figure 4a, row 2 left-hand side two panels), suggesting that the fourth ' $D$ ' domain of TG2 might have an important role in its nuclear export and regulation of the nuclear accumulation under ACR signal. Computer analysis for the prediction of leucine-rich NES found a putative NES at position ${ }^{657}$ LHMGLHKL ${ }^{664}$ near the $\mathrm{C}$ terminus domain in TG2. We treated $\mathrm{JHH}-7$ cells overexpressing TG2 (ABCD) and TG2 (CD) with leptomycin B (LMB), an inhibitor of exportin-1 (Figure 4b). The inhibitor successfully induced nuclear accumulation of TG2 (ABCD) and TG2 (CD) in the absence of $A C R$, suggesting that $D$ domain possess leucine-rich NESmediating nuclear export of TG2. To confirm whether the putative NES sequence is functional, we prepared EGFPtagged point mutation in TG2, where the three leucine residues within the putative NES sequence were all changed to glutamine (Figure 4c). Mutation of the leucine residues to glutamine residues increased nuclear accumulation of the TG2 in EtOH-treated control cells (Figure 4c, compare row 1 with row 2). Quantitative representations for the images in Figure 4 are shown in Supplementary Figures 2A and 2C.

TG2 formed a trimeric complex with importins-a and $\boldsymbol{\beta}$. To identify the co-factor(s) for nuclear import of TG2, physical interactions between TG2 and importin family proteins (importins- $\alpha 1,-\alpha 3,-a 5$ and $-\beta$ ) were examined. TG2 bound with glutathione S-transferase (GST)-tagged importins - $\beta$ (Figure 5a, lane 2), individually with importins $-a 5,-a 1$ and - $a 3$ (Figure 5a, lanes 3, 5 and 7) and with the importin- $a$ proteins in presence of importin- $\beta$ (Figure $5 a$, lanes 4,6 and 8 ). Comparing with importin- $\beta$, higher amounts of importin $a$ subfamily proteins interacted with TG2 in the order of importins $a 3>a 1 \approx a 5$ (Figure 5a), suggesting that importin-a3 might work as a major carrier for TG2 nuclear entry. Therefore, we used importin- $\alpha 3$ in the next experiments. In the presence of importin- $\beta$, increased amount of TG2 interaction was observed (compare lanes 3, 5 and 7 with 4, 6 and 8), suggesting the formation of trimeric complex of TG2/importin- $\alpha$ /importin- $\beta$. The interaction between TG2 and importin- $\alpha 3 /$ importin- $\beta$ was not altered in the presence of Z-DON, suggesting that the interaction was independent of TG2 activity (Supplementary Figure 3). We next, explored if the 14-amino acid TG2 NLS peptide 'AEKEETGMAMRIRV' might work as a competitive inhibitor for formation of the TG2/importin- $\alpha 3 /$ importin- $\beta$ trimeric complex. We found a significant decrease in binding of TG2 with importin- $a 3$ in the presence of this peptide (Figure 5b, lane 5), but not with SV40 NLS peptide (Figure 5b, lane 3) and TG2 NES peptide (Figure $5 b$, lane 4), thus verifying that TG2 forms TG2/importin- $\alpha 3 /$ importin- $\beta$ trimeric complex, at least in part, through the newly identified NLS. We also examined the physical interactions between TG2 and exportin-1. TG2-bound, GST-tagged exportin-1 (Figure 5c, lane 2) and the binding was significantly inhibited in the presence of LMB (Figure 5c, compare lanes 2 with 7), but ACR did not interfere with TG2-exportin-1 binding (Figure 5c, compare lane 2 with lanes 4 and 5). Finally, we verified in situ association of TG2 with importins- $\alpha 3,-\alpha 5$ and $-\beta$ using proximity ligation assay (PLA) technique. In this assay the association is shown by red dots in the cells. ${ }^{40}$ Each dot in the $\mathrm{JHH}-7$ cell represented physical association between TG2 and importin proteins (Figure 5d, columns 2, 5 and 8).

ACR accelerated the formation of 'TG2/importin-a/importin- $\boldsymbol{\beta}$ ' trimeric complex. Next we examined the effect of ACR on binding ability of TG2 with importins. We observed 


\begin{tabular}{|c|c|c|c|c|c|}
\hline \multirow[t]{2}{*}{ a } & & \multicolumn{4}{|c|}{479} \\
\hline & & 14 & & 587 & 687 \\
\hline TG2 (ABCD) & EGFP & A & B & C & D \\
\hline TG2 (ABC) & EGFP & A & B & C & $\Delta$ \\
\hline TG2 (AB) & $2 \times$ EGFP & A & B & $\Delta$ & $\Delta$ \\
\hline TG2 (C) & 2XEGFP & & & C & $\Delta$ \\
\hline TG2 (1-479) & $2 \times E G F P$ & A & B & $\Delta$ & $\Delta$ \\
\hline TG2 (465-479) & 2xEGFP & & & $\Delta$ & $\Delta$ \\
\hline Mock & 2xEGFP & & & & \\
\hline
\end{tabular}

b

1 Mock
2 TG2 (ABCD)
$1-687$

3 TG2 (ABC)
$1-586$

4 TG2 (AB)

$1-465$

5 TG2 (C)

466-586
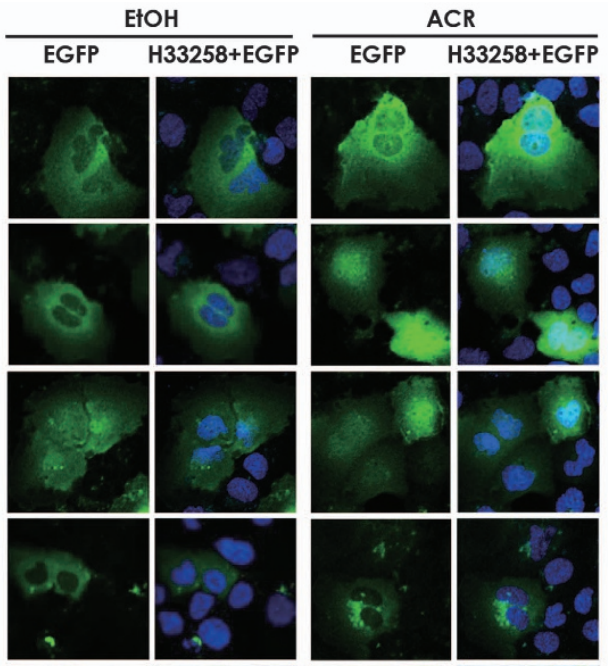
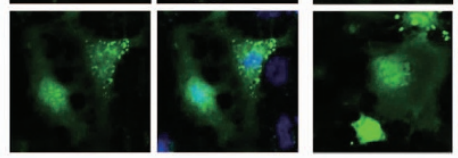

3

1

d

C

1

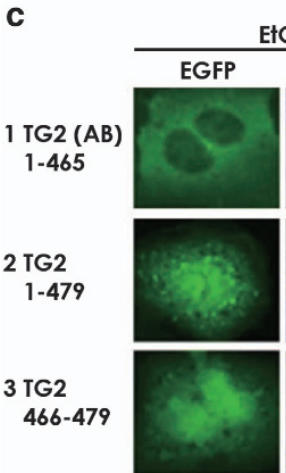

E†OH
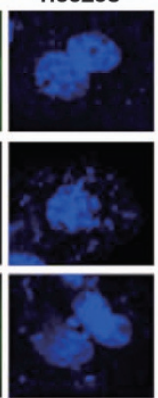

2

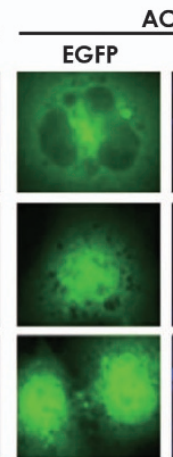

3 H33258

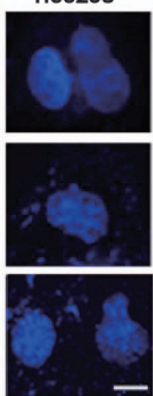

4

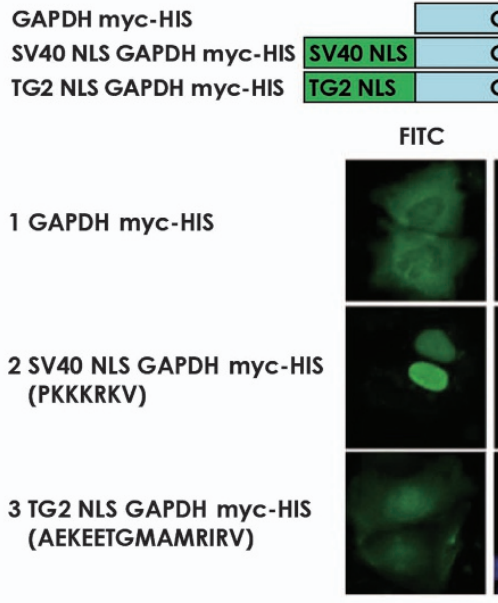

\begin{tabular}{l|l|l|}
\hline GAPDH & myc & HIS \\
\hline GAPDH & myc & HIS \\
\hline GAPDH & myc & HIS \\
\hline
\end{tabular}

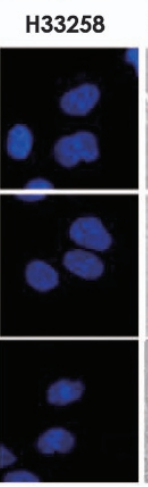

2

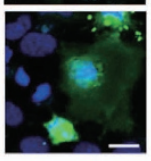

4

Figure 3 Identification of a novel NLS sequence in TG2. JHH-7 cells were seeded at $2 \times 10^{5}$ cells per 35 -mm dishes containing glass coverslips coated with Type-I C collagen, and were transiently transfected with $0.8 \mu \mathrm{g}$ of each of various EGFP-tagged TG2 and its fragments expressing vectors whose schematic structures are presented in a-c. Twentyfour hours after the transfection with the indicated vectors, the cells were treated with either $0.1 \% \mathrm{EtOH}$ (left-hand side two columns) or $10 \mu \mathrm{M}$ ACR (right-hand side two columns) for the next $10 \mathrm{~h}$. The cells were then fixed, stained with $\mathrm{H} 33258$ and observed under a confocal microscope. Green fluorescence from EGFP (the first and third columns) along with blue fluorescence of $\mathrm{H} 33258$ (the second and fourth columns) were monitored (d) Forty-eight hours after the transfection with the indicated GAPDH myc-HIS fused with either SV40 NLS or a novel TG2 NLS, the cells were fixed and immunostained using a FITC-tagged antibody against myc and co-stained with H33258. Green fluorescence from FITC (the first column) along with blue fluorescence of $\mathrm{H} 33258$ (the second column) was monitored under a confocal microscope. A scale bar, $20 \mu \mathrm{m}$. A representative result from three independent experiments with similar results is presented

that incubating TG2 with ATP decreased its ability to form the trimeric complex with importin- $\alpha 3$ /importin- $\beta$ (Figure 6a, compare lane 1 with lane 4). Inclusion of $\mathrm{EtOH}$ restored the binding ability of TG2 and ACR further stimulated trimeric complex formation in the presence of ATP (compare lane 3 with lane 6). Effect of ACR in binding of TG2 with importin family proteins was further verified by co-immunoprecipitation of importin- $\alpha 3$ and $\beta$. TG2-bound importin- $\alpha 3$ and $-\beta$ in $\mathrm{JHH}-7$ cells treated either with $0.1 \% \mathrm{EtOH}$ or $10 \mu \mathrm{M}$ ACR were co-immunoprecipitated from cell lysates using anti-TG2 antibody (CUB 7402) and determined by western blotting. We observed that binding of TG2 with importin- $a 3$ and $\beta$ in $\mathrm{JHH}-7$ cells increased by 1.9- and 1.3-folds, respectively, after treatment with $10 \mu \mathrm{M}$ ACR (Figure 6b).

We also observed a time-dependent increase in in situ binding of TG2 and importin- $\beta$ in ACR-treated $\mathrm{JHH}-7$ cells by 
a

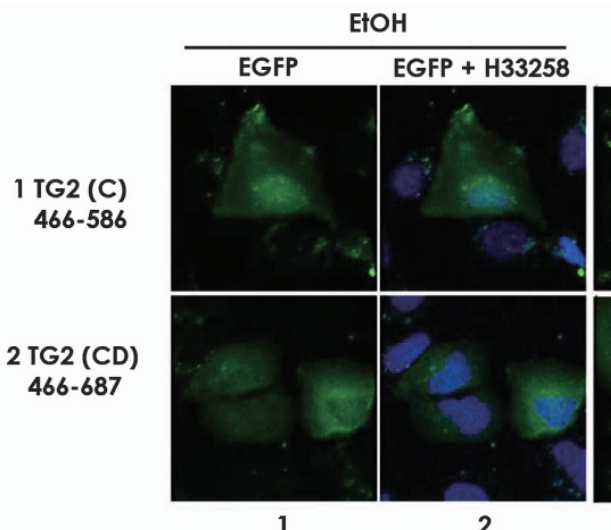

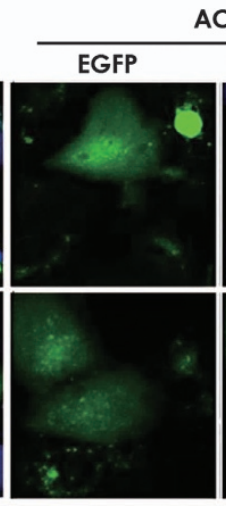

3 ACR EGFP + H33258

b

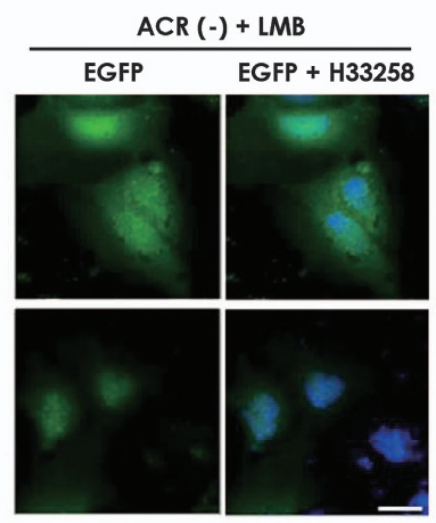

1

2

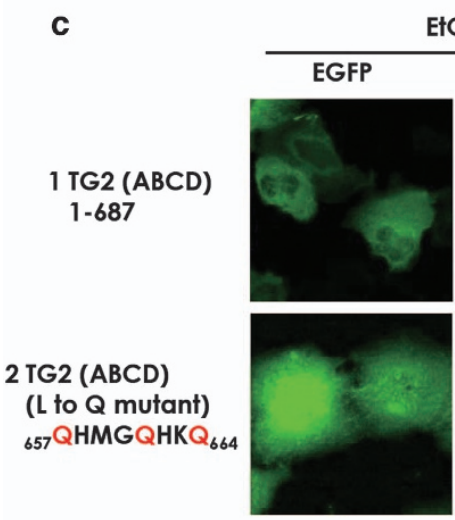

1
EłOH H33258
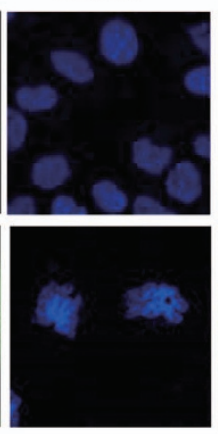

2

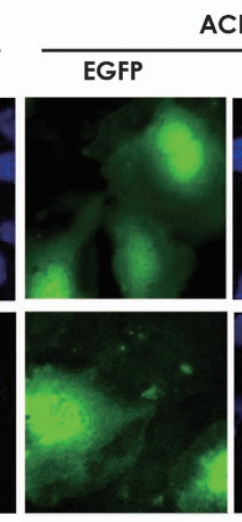

3

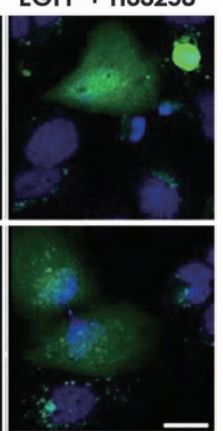

4

Figure 4 Identification of a nuclear export signal in TG2. JHH-7 cells were seeded as before and were transiently transfected with $0.8 \mu \mathrm{g}$ of the indicated EGFP-tagged, TG2 mutant-expressing vector. Twenty-four hours after the transfection with the indicated vectors, the cells were treated with $0.1 \% \mathrm{EtOH}$ ( $\mathbf{a}$ and $\mathbf{c}$, left-hand side two columns) or $10 \mu \mathrm{M}$ ACR (b, left-hand side two columns; and a and c, right-hand side two columns) or $20 \mathrm{ng} / \mathrm{ml}$ LMB (b, right-hand side two columns) for the next $10 \mathrm{~h}$. The cells were then fixed, stained with $\mathrm{H} 33258$ and observed under a confocal microscope. Green fluorescence derived from EGFP was monitored along with blue fluorescence from H33258. A scale bar, $20 \mu \mathrm{m}$. Nuclear EGFP intensities for TG2 (ABCD) and TG2 (ABCD) NES mutant treated with $0.1 \%$ EtOH (c, left-hand side two columns) and $10 \mu \mathrm{M}$ ACR (c, right-hand side two columns) are presented under corresponding each panel as mean \pm S.D. $(n=6)$. Briefly, EGFP florescence signal overlapped with $\mathrm{H} 33258$ florescence signal was quantitated using co-localization tool of ZEN software (Carl Zeiss, Inc., Jena, Germany) and presented as the mean EGFP intensities in the nucleus under the corresponding panels. A representative result from two independent experiments with similar results is presented

using PLA technique (Figure 6c). The appearance of red dots in the nucleus (shown by white arrow heads) at 5 and $7 \mathrm{~h}$ after ACR treatment cells signifies translocation of TG2 into the nucleus. The nuclear translocation was not observed in EtOH-treated cells. This observation is consistent with our results presented in Figure 2.

\section{Discussion}

In this paper, we demonstrated that both, a newly identified 14-amino acid NLS located at the beginning of the ' $C$ ' domain and 'TG2/importin-as/importin- $\beta$ ' trimeric complex formation were involved in nuclear import of TG2, while exportin-1- 
a

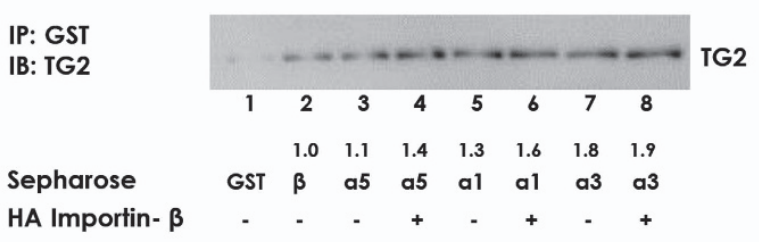

b

IP: GST
IB: TG2

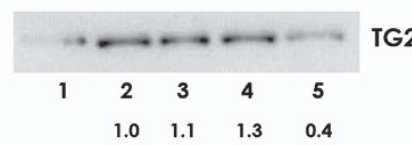

Sepharose GST a3 a3 a3 a3

HA Importin- $\beta+++++$

SV40 NLS - - + + - -

$\begin{array}{llllll}\text { TG2 NES } & - & - & - & + & - \\ \text { TG2 NLS } & - & - & - & - & +\end{array}$
C

IP: GST

IB: TG2

Sepharose

EłOH (99.5\%) $\mu \mathrm{L}$

ACR (1mM ) $\mu \mathrm{L}$ LMB $(10 \mu \mathrm{g} / \mathrm{mL}) \mu \mathrm{L}$

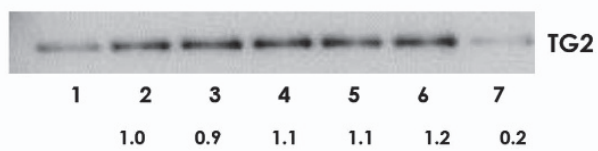

GST Exp-1 Exp-1 Exp-1 Exp-1 Exp-1 Exp-1

- $\quad 0.5 \quad-\quad$ - 0.5 -

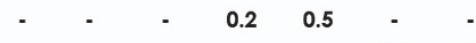

d

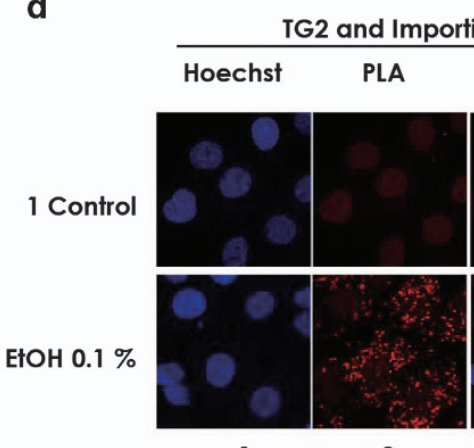

1

2

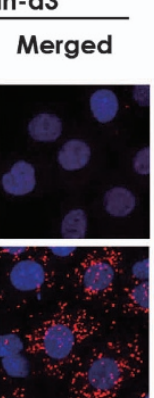

3

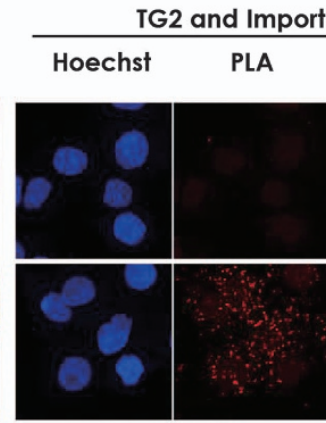

4

5

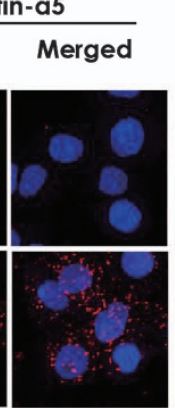

6

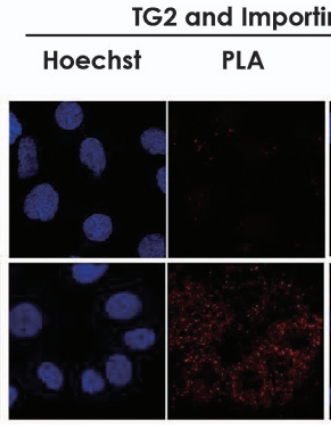

7

8

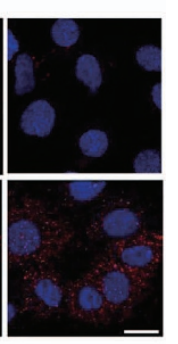

9

Figure 5 Co-factor(s) for nuclear import of TG2. Recombinant human TG2 (about $1.5 \mathrm{pmol}$ ) was incubated for $1 \mathrm{~h}$ at room temperature with glutathione sepharose 4B beads conjugated with six times molar excess of (a) GST (lane 1), GST-tagged importin- $\beta$ (lane 2), - $\alpha 5$ (lane 3), $-\alpha 1$ (lane 4) and - $\alpha 3$ (lane 7) or with GST-tagged importin- $\alpha 5, \alpha 1, \alpha 3$ in presence of HA-tagged importin- $\beta$ in (lane 4, 6 and 8 respectively). (b) GST (lane 1) or GST-importins- $\alpha 3 /$ HA-importin- $\beta$ complex (lane 2) or in presence of peptide SV40 NLS, TG2 NES and TG2 NLS (lane 3, 4 and 5, respectively) (c) GST (lane 1) or GST-tagged exportin-1 (Exp-1) in the presence or absence of $0.1 \%$ EtOH, $1 \mathrm{mM} \mathrm{ACR} \mathrm{and} 10 \mu \mathrm{g} / \mathrm{ml}$ LMB as indicated. After spin-down, proteins were eluted with SDS-PAGE sample buffer and TG2 level in each pull down obtained under each condition were determined by western blotting using an antibody against TG2. A representative image, showing intensity value of each blot relative to lane 2 is presented as mean for three independent experiments (a) or as mean for two independent experiments (b and c). Specificity in the immunoprecipitation experiment of the TG2-exportin-1 complex was ensured in the control experiment (Supplementary Figure 7). (d) JHH-7 cells were seeded at $1 \times 10^{3}$ cells per well in 96-well plate and incubated at $37^{\circ} \mathrm{C}$ overnight. PLA was performed according to the manufacturer's instruction. In control (row 1), the cells were treated with media for $3 \mathrm{~h}$ and cells were fixed, permeabilized and no antibodies were used against TG2 and importins for PLA assay. While in others, cells were treated with $0.1 \%$ EtOH for $3 \mathrm{~h}$, fixed, permeabilized and treated with combinations of mouse anti-TG2 (CUB7402) and rabbit anti-KPNA4 (left panel, row 2), mouse antiTG2 (CUB7402) and rabbit anti-SRP-1 (central panel, row 2) or mouse anti-TG2 (CUB7402) and rabbit anti-importin- $\beta$ (right panel, row 2). After amplification and staining with $\mathrm{H} 33258$, the cells were observed under a confocal microscope. Red fluorescence dots derived from amplification of detected protein interaction was monitored with blue fluorescence from H33258. A scale bar $=20 \mu \mathrm{m}$. A representative image from three independent experiments with similar results is presented

dependent, putative leucine-rich NES located at the ' $D$ ' domain of TG2 was responsible for its shuttling back to the cytoplasm. We have also illustrated that ACR promoted the trimeric complex formation and induced accumulation of TG2 in the nucleus of the treated $\mathrm{JHH}-7$ cells leading to their apoptosis.

Previously, we reported that crosslinking of Sp1 as a mechanism responsible for pro-apoptotic pathway by nuclear TG2 in the liver. ${ }^{19-22}$ Here, by using time lapse monitoring of a single cell, we confirmed that ACR induces nuclear accumulation of TG2 in $\mathrm{JHH}-7$ cells and leads the cell to apoptosis. Using a combination of inhibitors of TG2 activity (either R283 or Z-DON) and various TG2 mutants including the 'AB' that has transamidase activity but deficient in nuclear accumulation (Supplementary Figure 4A), we demonstrated a link between nuclear accumulations of TG2 and exerting its transamidation activity therefore the pro-apoptotic pathway of TG2 in the liver. We also observed that apoptosis induced by $\mathrm{ACR}$ in cell overexpressing TG2 in cytosol cannot be prevented by a TG2 inhibitor (Figure 2a). However, cotreatment of the cells with zDEVD, a caspase- 3 inhibitor and a TG2 inhibitor decreased apoptosis of both types of cells overexpressing TG2 in nucleus as well as cytosol (data not shown). This result corroborates our previous finding that both caspase-3- and TG2-mediated mechanisms for ACR-induced cell death. ${ }^{19}$ We observed nuclear accumulation of a TG2 mutant-lacking transamidase activity but containing both NLS and NES sequences, namely 'CD', leading the cells to apoptosis. The rate of accumulation and extent of cell death was rather escalated by ACR (Supplementary Figure 4B). We speculate that relative better access of NLS present in C domain of TG2 (CD), which would otherwise be structurally 

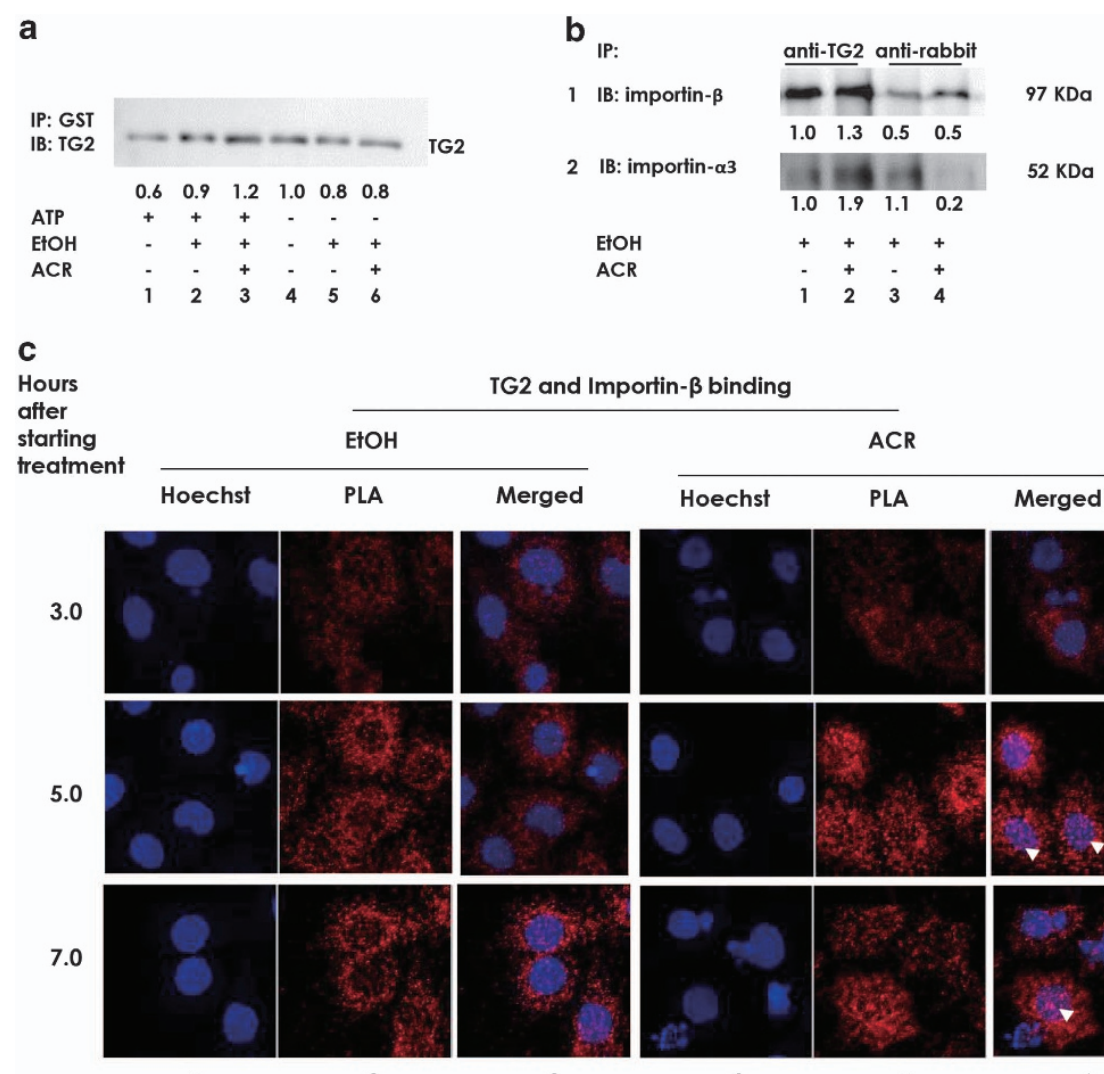

TG2 and Importin- $\beta$ binding
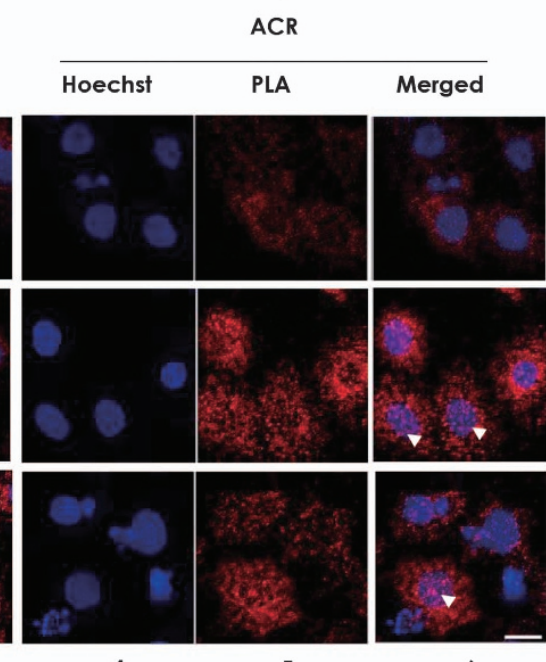

Figure 6 Effect of ACR in trimeric complex formation. (a) Recombinant human TG2 (1.5 pmol) was incubated for $1 \mathrm{~h}$ at room temperature with glutathione sepharose 4B beads conjugated with six times molar excess of GST-importins- $\alpha 3 / \mathrm{HA}$-tagged importin- $\beta$ complex in the presence or absence of ATP, EtOH or ACR as indicated. After spin-down, proteins were eluted with SDS-PAGE sample buffer and TG2 levels in each co-precipitate obtained under each condition were determined by western blotting using an antibody against TG2. A representative result from two independent experiments with similar results is presented. (b) $\mathrm{JHH}-7$ cells were seeded at $1 \times 10^{6} \mathrm{cells}$ per 10 -cm dish overnight. The cells were then treated with $0.1 \% \mathrm{EtOH}$ (column 1 and 3 ) or $10 \mu \mathrm{M} \mathrm{ACR}$ (column 2 and 4 ) for next $5 \mathrm{~h}$. The cells were lysed using Tris buffer (pH 7.4) with 1\% Triton X-100, $0.1 \mathrm{mg} / \mathrm{ml} \mathrm{PMSF}$ and the protease inhibitor cocktail. Importin- $\beta$ (row 1) and importin- $\alpha 3$ (row 2) were co-immunoprecipitated using TG2 antibody (CUB7402) from samples containing equal amount of total protein determined by bicinchoninic acid (BCA) protein assay method. After precipitation, proteins were eluted with SDS-PAGE sample buffer and levels of importin- $\beta$ and $-\alpha 3$ in each co-precipitation obtained under each condition were determined by western blotting using an antibody indicated. (c) JHH-7 cells were seeded at $1 \times 10^{3}$ cells per well in 96-well plate and incubated at $37^{\circ} \mathrm{C}$ overnight. The cells were then treated with $0.1 \%$ EtOH (columns 1-3) or $10 \mu \mathrm{M} \mathrm{ACR}$ (columns $4-6$ ) for the next 3,5 and $7 \mathrm{~h}$ (rows 1-3). The cells were then fixed and PLA was performed as per manufacturer's instruction. The cells were treated with mouse anti-TG2 (CUB 7402) and rabbit antiimportin- $\beta$. After amplification and staining with $\mathrm{H} 33258$, the cells were observed under a confocal microscope. Red fluorescence dots derived from amplification of detected protein interaction were monitored with blue fluorescence from $\mathrm{H} 33258$. A scale bar, $20 \mu \mathrm{m}$. A representative image from two independent experiments is presented. White arrow heads signify the nuclear TG2-importin $\beta$ complex.

hindered in the presence of large 'AB' domain in the closed conformation of TG2, might be the reason for the nuclear accumulation. However, increased apoptosis by the cells expressing nuclear TG2 (CD) was unexpected. We do not know the reason, but speculate that overexpressed CD might act as a tag for endogenous TG2 to get into the nucleus given that overexpressed CD might interact with endogenous TG2. We are now testing this hypothesis.

We also demonstrated that TG2 shuttled to and fro between nucleus and cytoplasm. By overexpressing TG2 fragments in $\mathrm{JHH}-7$ cells, we showed that TG2 was imported into the nucleus via a newly identified 14-amino acid NLS sequence $\left({ }^{466}\right.$ AEKEETGMAMRIRV $\left.{ }^{479}\right)$ within the 'C' domain. The putative NLS motifs p-nls1 (aa259-263) and p-nls2 (aa597-602) are not functional in TG2 as both ' $A B$ ' and ' $D$ ' domain did not cause or increase the nuclear accumulation (Figures $3 b$, row 4 and $4 a$, row 2). We confirmed the nuclear localizing ability of the novel NLS by fusing it with GAPDH-tagged myc-HIS protein and verified its binding with importin- $a 3$ by using the NLS peptides in competition binding assay with rhTG2. The identified novel NLS sequence is present only in TG2 among the TG family proteins but it is conserved in TG2 protein among various mammalian species (Supplementary Figure 5).

TG2 also contains a computationally predicted putative leucine-rich NES at the position ${ }^{657}$ LHMGLHKL ${ }^{664}$, near the C terminus. ${ }^{33,34}$ We showed that the putative leucine-rich NES sequence is functional and exportin-1 dependent. Point mutation of all the leucine residues to glutamine residues in the sequence demolished the nuclear export ability of NES confirming its role in nuclear export of TG2. The NES sequence shares one of the generally accepted consensus putative NES motifs critical for exportin-1 binding, thereby being responsible for the export of proteins from the nucleus to the cytoplasm in several organisms. ${ }^{35-37}$ On the other hand, the NES sequence is not conserved among the TG protein family as well as among various mammalian species' TG2 
protein. The sequence is unique for human and monkey's TG2 (Supplementary Figure 6).

Previously, we reported that EtOH-treated hepatocytes showed enhanced expression of importin-a3, accompanied by nuclear localization of TG2. ${ }^{20}$ Thus, we hypothesized that importin- $a 3$ may have a role in nuclear localization of TG2. Peng et al. ${ }^{31}$ reported that importin- $\alpha 3$ might be involved in the nuclear translocation of TG2 based on binding of these proteins in yeast two-hybrid analysis; however, they did not provide exact binding site for importin- $a 3$. We examined the interactions between TG2 and importin- $a$ proteins (Figure 5a). The current data showed that TG2 interacted with each of importin- $\alpha 1, a 3, a 5$ and $\beta$ individually and in the presence of importin- $\beta$-forming trimeric complexes with importin- $\alpha 1,-\alpha 3$ and -a5. Importantly, the newly identified NLS sequence peptide blocked this interaction (Figure 5b). Furthermore, strikingly, the trimeric complex formation was weakened in the presence of ATP but restored and rather enhanced by ACR. The NLS sequence that we have found in TG2 has been reported to contain binding sites for ATP and GTP. TG2 in closed conformation is inactive in ATP/GTP-bound forms. We speculate that the 14-amino acid NLS sequence is available for binding when TG2 is in open conformation, and ACR might induce the conformational change in TG2 enabling it to specifically enhance nuclear accumulation of TG2 in ACR-treated HCC cells by enhancing the TG2/importin- $\alpha$ /importin- $\beta$ trimeric complex formation. More study is needed to see the effect of $A C R$ in the regulation of conformational change in TG2. Also, though we observed that ACR does not have effect in binding between TG2 and exportin-1, however, we cannot rule out the possibility of effect of ACR in nuclear export of TG2. We are now studying this possibility.

\section{Materials and Methods}

Materials. ACR (NIK-333) was provided by Kowa Company Ltd. (Tokyo, Japan). $\mathrm{EtOH}$ was obtained from Wako Industries (Osaka, Japan) and was used as a primary solvent. Recombinant human TG2 and Z-DON were purchased from Zedira (Darmstadt, Germany). Anti-TG2 CUB7402 was from Neomarker (Fremont, Canada). Anti-myc-FITC was from Invitrogen (Waltham, MA, USA). CRM1 antibody was from Thermo Scientific (Rockford, IL, USA). Anti-KPNA4, anti-SRP1 and antiNTF97 were from Abcam (Cambridge, UK). Anti-Horseradish peroxide-conjugated goat anti-mouse IgG and anti-rabbit IgG were from Jackson ImmunoResearch Laboratories (West Grove, PA, USA). Hoechst 33258 came from CalbiochemNovabiochem (La Jolla, CA, USA). LMB was kindly supplied by Dr. Yoshida (Chemical Genomics Research Group, RIKEN Center for Sustainable Resource Science, Wako, Saitama, Japan). A TG2 inhibitor R283 was kindly provided as a gift by Dr. Griffin (Aston University, Birmingham, UK). ${ }^{13}$

Cells. A HCC cell line, JHH-7 cells were kindly supplied by Dr. Matsuura (Jikei University School of Medicine, Tokyo, Japan). The cell line was maintained in Dulbecco's Modified Eagle Medium (Wako Pure Chemical Industries, Osaka, Japan) containing $10 \%$ fetal bovine serum (Mediatech, Herndon, VA, USA), and grown at $37^{\circ}$ $\mathrm{C}$ in a humidified $5 \% \mathrm{CO}_{2}$ incubator. For chemical treatment, the cells were cultured in serum-free media containing appropriate concentrations of EtOH or ACR.

Plasmid and transfection. We named each of the four structural domains of TG2 as A, B, C, D domains starting from the $\mathrm{N}$ terminus. Expression vector for the EGFP-tagged TG2 mutants and myc-HIS-tagged GAPDH were amplified from TG2-pSG5 vector and GAPDH-pOTB7 vector (BC001601, Gene Engineering Division, RIKEN BioResourse Center), respectively, by PCR using synthetic oligonucleotides (Invitrogen) with appropriate restriction sites. The amplified products were ligated into pEGFP-C1 vector (Clontech Laboratories, Inc., Mountain View, CA, USA) for EGFPtagged TG2 mutants with EGFP at N-terminal site and pcDNA myc-HIS 3.1 vector for
myc-HIS-tagged GAPDH respectively. All the overexpressed proteins except TG2 (ABCD) showed almost similar stability (Supplementary Table 1), but this does not change the interpretation of the results presented. Cells grown for $24 \mathrm{~h}$ were transfected with appropriate vectors using Lipofectamine (Invitrogen) and Plus reagent (Invitrogen).

Staining of cells. Cells grown on coverslips were fixed with $10 \%$ formalin in phosphate-buffered saline. Cells were permeabilized with $0.1 \%$ Triton X-100 in phosphate-buffered saline, and stained with antibodies as indicated in the corresponding figures. Nucleus of the cell was stained with H33258. Digital images of the cells were taken by LSM 700 laser scanning confocal microscopy (Carl Zeiss, Inc.; Jena, Germany).

Time lapse imaging. Time lapse imagines of the treated $\mathrm{JHH}-7$ cells were taken using Zeiss's LSM 700 laser scanning confocal microscope maintaining the cells at $37^{\circ} \mathrm{C}$ in a humidified $5 \% \mathrm{CO}_{2}$ incubator unit. Cells showing membrane blebbing and shrinkage, after no further shrinkage, were considered as dead cells or else alive and the time as the cell death time.

Active caspase-3 quantitation. Quantitation of active caspase-3 was performed in duplicates using Quantikine ELISA kit (R\&D systems, Inc., McKinley Place, MN, USA) as per the manufacturer's protocol. Briefly, $\mathrm{JHH}-7$ cells treated with $10 \mu \mathrm{M}$ ACR or $0.1 \% \mathrm{EtOH}$ were collected along with the detached cells using extraction buffer containing protease inhibitors at 4,8 and $12 \mathrm{~h}$ of the treatment. After suitable dilution, biotin-ZVKD-fmk-labeled active caspase-3 (biotin-ZVKD-fmk is a component of Quantikine ELISA kit) in the cell lysates were measured according to the manufacturer's instructions.

GST pull-down assay. For binding study of TG2 and importin- $\alpha$ s, $100 \mathrm{ng}$ recombinant human TG2 was incubated for $1 \mathrm{~h}$ in Tris buffer $(\mathrm{pH} 7.6)$ containing $150 \mathrm{mM} \mathrm{NaCl}$ at room temperature with glutathione sepharose 4B beads (GE Healthcare, Uppsala, Sweden) conjugated with GST-tagged importin- $\beta,-\alpha 1,-\alpha 3,-\alpha 5$ or complexes of GST-tagged importin- $\beta$ and GST-tagged importin $(-\alpha 1,-\alpha 3,-\alpha 5)$, or complexes of GST importin $(-\alpha 1,-\alpha 3,-\alpha 5)$ and hemagglutinin (HA)-tagged importin$\beta$. For binding study of TG2 and importin- $\alpha$ s in the presence of ACR, glutathione sepharose $4 \mathrm{~B}$ beads conjugated with GST-tagged importin- $\alpha 3 / \mathrm{HA}$-tagged importin$\beta$ were incubated in the presence or absence of $20 \mu \mathrm{M} \mathrm{ACR}$ or $0.1 \% \mathrm{EtOH}$ with $100 \mathrm{ng}$ recombinant human TG2. In some samples, TG2 was pre-incubated with $500 \mu \mathrm{M}$ ATP. After spin-down, proteins were eluted with SDS-PAGE sample buffer and TG2 levels in co-precipitates under each condition were determined by western blotting using an antibody against TG2.

Co-immunoprecipitation. Co-immunoprecipitation was performed using Dynabeads protein $\mathrm{G}$ as per the manufacturer's protocol. Briefly, the treated $\mathrm{JHH}-7$ cells were lysed with ice-cold cell lysis buffer (Tris buffer, pH 7.4 containing 1\% Triton $\mathrm{X}-100,0.1 \mathrm{mg} / \mathrm{ml}$ PMSF and protease inhibitor cocktail). Samples were centrifuged and lysates were collected, $500 \mu \mathrm{g}$ of total protein cell lysates as determined by bicinchoninic acid protein assay were incubated with $1.5 \mathrm{mg}$ Dynabeads protein $\mathrm{G}$ or $\mathrm{A}$ (Life Technologies, Oslo, Norway) pre bound with either anti-TG2 CUB7402 $(0.5 \mu \mathrm{g})$ or CRM1 antibody $(0.5 \mu \mathrm{g})$. As a control anti-mouse or anti-rabbit non-immune antibodies were also used. After binding for $15 \mathrm{~min}$ with the cell lysates at room temperature, the beads were washed three times with wash buffer (PBS (pH 7.4) with 0.02\% Tween-20) before eluting with elution buffer ( $50 \mathrm{mM}$ glycine $(\mathrm{pH} 2.8)$ ) and boiled with SDS-PAGE sample buffer. Importin $\alpha 3$ and $\beta$ levels in the precipitates under each condition were determined by western blotting using an antibody against importin- $\alpha 3,-\beta$ or TG2.

Western blotting. Western blotting was performed as before ${ }^{19}$ using suitable anti-TG2 CUB7402 (1:5000), anti-KPNA4 (1:2000), anti-SRP1 (1:1000), antiNTF97 $(1: 300)$ and anti-CRM1 $(1: 1000)$ dilution and were probed either with horseradish peroxidase goat anti-mouse IgG $(1: 2000$ dilution) or goat anti-rabbit $\operatorname{lgG}(1: 2000$ dilution). Reactants were detected with Enhanced Chemiluminescence reagents (GE Healthcare, Buckinghamshire, UK).

Proximity ligation assay. PLA was performed using Duolink in situ PLA probe anti-Rabbit PLUS, anti-Mouse Minus and detection reagent red (Olink Bioscience Uppsala, Sweden) according to the manufacturer's instructions. Briefly, $\mathrm{JHH}-7$ cells were treated with $10 \mu \mathrm{M}$ ACR or $0.1 \% \mathrm{EtOH}$. The cells were fixed after the mentioned time. The cells were then blocked and incubated with mouse anti-TG2 CUB7204 and rabbit anti-importin(s) as indicated in the corresponding figure legends. Minus probe that identifies mouse antigen and plus probe that identifies rabbit 
antigen were added. The minus and plus probes were ligated and the signal was amplified using ligation and development steps. ${ }^{40}$ The developed fluorescence was then observed under Zeiss LSM 700 laser scanning confocal microscope.

Statistical analyses. Quantitative data are shown as mean \pm S.D. Statistical analyses were performed using GraphPad Prism version 6.0 for Windows (GraphPad Software, San Diego, CA, USA). ${ }^{*} P$-value $<0.05$ and ${ }^{* *} P$-value $<0.01$ were considered as statistically significant.

\section{Conflict of Interest}

The authors declare no conflict of interest. Although $\mathrm{NI}$ is an employee of Kowa Company Ltd., this did not affect the experimental design or interpretation of the results.

Acknowledgements. This work was supported partly by Grant-in-Aids from the Ministry of Education, Science, Sports and Culture and by grant from the RIKEN CLST (to SK) and the JSPS Core to Core Program, Advanced Research Networks (to HK). Rajan Shrestha has been awarded International Program Associate (IPA) fellowship from RIKEN and Tokyo Medical and Dental University, Japan and Ronak Shrestha has been awarded International Program Associate (IPA) fellowship from RIKEN and Tokyo Institute of Technology, Japan.

1. Fesus L, Szondy Z. Transglutaminase 2 in the balance of cell death and survival. FEBS Lett 2005; 579: 3297-3302.

2. Liu S, Cerione RA, Clardy J. Structural basis for the guanine nucleotide-binding activity of tissue transglutaminase and its regulation of transamidation activity. Proc Natl Acad Sci USA 2002; 99: 2743-2747.

3. Han B-G, Cho J-W, Cho YD, Jeong K-C, Kim S-Y, Lee BI. Crystal structure of human transglutaminase 2 in complex with adenosine triphosphate. Int J Biol Macromol 2010; 47: 190-195.

4. Pinkas DM, Strop P, Brunger AT, Khosla C. Transglutaminase 2 undergoes a large conformational change upon activation. PLOS Biol 2007; 5: 2788-2796.

5. Casadio R, Polverini E, Mariani P, Spinozzi F, Carsughi F, Fontana A et al. The structural basis for the regulation of tissue transglutaminase by calcium ions. Eur J Biochem 1999; 262: 672-679.

6. Venere AD, Rossi A, Matteis FD, Rosato N, Agro AF, Mei G. Opposite effects of $\mathrm{Ca}(2+)$ and GTP binding on tissue transglutaminase tertiary structure. J Biol Chem 2000; 275: 3915-3921.

7. Nakaoka H, Perez DM, Baek KJ, Das T, Husain A, Misono K et al. Gh: a GTP-binding protein with transglutaminase activity and receptor signaling function. Science 1994; 264: 1593-1596.

8. Lorand L, Graham RM. Transglutaminases: crosslinking enzymes with pleiotropic functions. Nat Rev Mol Cell Biol 2003; 4: 140-156.

9. Wu J, Liu S-L, Zhu J-L, Norton PA, Nojiri S, Hoek JB et al. Roles of tissue transglutaminase in ethanol-induced inhibition of hepatocyte proliferation and alpha 1-adrenergic signal transduction. J Biol Chem 2000; 275: 22213-22219.

10. Begg GE, Carrington L, Stokes PH, Matthews JM, Wouters MA, Husain A et al. Mechanism of allosteric regulation of transglutaminase 2 by GTP. Pro Natl Acad Sci USA 2006; 103 : 19683-19688.

11. Kuo T-F, Tatsukawa $H$, Kojima S. New insights into the functions and localization of nuclear transglutaminase 2. FEBS J 2011; 278: 4756-4767.

12. Fesus $L$, Piacentini $M$. Transglutaminase 2 : an enigmatic enzyme with diverse functions. Trends Biochem Sci 2002; 27: 534-539.

13. Griffin M, Casadio R, Bergamini CM. Transglutaminases: Nature's biological glue. Biochem J 2002; 368: 377-396.

14. lismaa SE, Mearns BM, Lorand L, Graham RM. Transglutaminases and disease: lessons from genetically engineered mouse models and inherited disorders. Physiol Rev 2009; 89: 991-1023.

15. Muto Y, Moriwaki H, Ninomiya M, Adachi S, Saito A, Takasaki KT et al. Prevention of second primary tumors by an acyclic retinoid, polyprenoic acid, in patients with hepatocellular carcinoma. N Engl J Med 1996; 334: 1561-1567.

16. Takai K, Okuno M, Yasuda I, Matsushima-Nishiwaki R, Uematsu T, Tsurumi H et al. Prevention of second primary tumors by an acyclic retinoid in patients with hepatocellular carcinoma. Updated analysis of the long-term follow-up data. Intervirology 2005; 48: 39-45.

17. Matsushima-Nishiwaki R, Okuno M, Adachi S, Sano T, Akita K, Moriwaki H et al. Phosphorylation of retinoid $X$ receptor alpha at serine 260 impairs its metabolism and function in human hepatocellular carcinoma. Cancer Res 2001; 61: 7675-7682.
18. Matsushima-Nishiwaki R, Okuno M, Takano Y, Kojima S, Friedman SL, Moriwaki H. Molecular mechanism for growth suppression of human hepatocellular carcinoma cells by acyclic retinoid. Carcinogenesis 2003; 24: 1353-1359.

19. Tatsukawa H, Sano T, Fukaya $Y$, Ishibashi N, Watanabe M, Okuno M et al. Dual induction of caspase 3-and transglutaminase-dependent apoptosis by acyclic retinoid in hepatocellular carcinoma cells. Mol Cancer 2011; 10: 1-11.

20. Tatsukawa H, Fukaya Y, Frampton G, Martinez-Fuentes A, Suzuki K, Kuo T-F et al. Role of transglutaminase 2 in liver injury via cross-linking and silencing of transcription factor Sp1. Gastroenterology 2009; 136: 1783-1795.

21. Tatsukawa $\mathrm{H}, \mathrm{Kojima} \mathrm{S.} \mathrm{Recent} \mathrm{advances} \mathrm{in} \mathrm{understanding} \mathrm{the} \mathrm{roles} \mathrm{of} \mathrm{transglutaminase} 2$ in alcoholic steatohepatitis. Cell Biol Int 2010; 33: 325-334.

22. Kuo T-F, Tatsukawa H, Matsuura T, Nagatsuma K, Hirose S, Kojima S. Free fatty acids induce transglutaminase 2-dependent apoptosis in hepatocytes via ER stress-stimulated PERK pathways. J Cell Physiol 2012; 227: 1130-1137.

23. Lesort M, Attanavanich K, Zhang J, Johnson GVW. Distinct nuclear localizaiton and activity of tissue transglutaminase. J Biol Chem 1998; 273: 11991-11994.

24. Mann AP, Verma A, Sethi G, Manavathi B, Wang H, Fok JY et al. Overexpression of tissue transglutaminase leads to constitutive activation of nuclear factor ${ }_{\mathrm{K}} \mathrm{B}$ in cancer cells: delineation of a novel pathway. Cancer Res 2006; 66: 8788-8795.

25. Takeuchi $\mathrm{Y}$, Ohashi H, Birckbichler PJ, Ikejima T. Nuclear translocation of tissue type transglutaminase during sphingosine-induced cell death: a novel aspect of the enzyme with DNA hydrolytic activity. Z Naturforsch C 1998; 53: 352-358.

26. Campisi A, Caccamo D, Raciti G, Cannavo G, Macaione V, Curro M. Glutamate-induced increases in transglutaminase activity in primary cultures of astroglial cells. Brain Res 2003; 978: 24-30.

27. Stewart M. Molecular mechanism of the nuclear protein import cycle. Nat Rev Mol Cell Biol 2007; 8: 195-208.

28. Pemberton LF, Pascha BM. Mechanism of receptor-mediated nuclear import and nuclear export. Traffic 2005; 6: 187-198.

29. Goldfarb DS, Corbett AH, Mason DA, Harreman MT, Adam SA. Importin $\alpha$ : a multipurpose nuclear-transport receptor. Trends Cell Biol 2004; 14: 505-514.

30. Kohler M, Speck C, Christiansen M, Bischoff FR, Prehn S, Haller $\mathrm{H}$ et al. Evidence for distinct substrate specificities of importin $\alpha$ family members in nuclear protein import. Mol Cell Biol 1999; 19: 7782-7791.

31. Peng $X$, Zhang $Y$, Zhang H, Graner S, Williams JF, Levitt ML et al. Interaction of tissue transglutaminase with nuclear transport protein importin-alpha3. FEBS Lett 1999; 446: 35-39.

32. Greenspan D, Palese P, Krystal M. Two nuclear location signals in the influenza virus NS1 nonstructural protein. J Virol 1988; 62: 3020-3026.

33. Cour TI, Kiemer L, Mølgaard A, Gupta R, Skriver K, Brunak S. Analysis and prediction of leucine-rich nuclear export signals. Protein Eng Des Sel 2004; 17: 527-536.

34. Kojima S, Kuo T-F, Tatsukawa H. Regulation of transglutaminase-mediated hepatic cell death in alcoholic steatohepatitis and non-alcoholic steatohepatitis. J Gastroenterol Hepatol 2012; Suppl 2: 52-57.

35. Fornerod M, Ohno M, Yoshida M, Mattaj IW. CRM1 is an export receptor for leucine-rich nuclear export signals. Cell 1997; 90: 1051-1060.

36. Haasen D, Kohler C, Neuhaus G, Merkle T. Nuclear export of proteins in plants: AtXPO1 is the export receptor for leucine-rich nuclear export signals in Arabidopsis thaliana. Plant $J$ 1999; 20: 695-705.

37. Stade K, Ford CS, Guthrie C, Weis K. Exportin 1 (Crm1p) is an essential nuclear export factor. Cell 1997; 90: 1041-1050.

38. McConoughey SJ, Basso M, Niatsetskaya ZV, Sleiman SF, Smirnova NA, Langley BC et al. Inhibition of transglutaminase 2 mitigates transcriptional dysregulation in models of Huntington's disease. EMBO Mol Med 2010; 2: 349-370.

39. Johnson TS, Scholfield $\mathrm{Cl}$, Parry J, Griffin M. Induction of tissue transglutaminase by dexamethasone: its correlation to receptor number and transglutaminase-mediated cell death in a series of malignant hamster fibrosarcomas. Biochem J 1998; 331: 105-112.

40. Söderberga O, Leuchowiusa K-J, Gullbergb M, Jarviusa M, Weibrechta I, Larssonc L-G et al. Characterizing proteins and their interactions in cells and tissues using the in situ proximity ligation assay. Methods 2008; 45: 227-232.

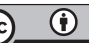

Cell Death and Disease is an open-access journal published by Nature Publishing Group. This work is licensed under a Creative Commons Attribution 4.0 International License. The images or other third party material in this article are included in the article's Creative Commons license, unless indicated otherwise in the credit line; if the material is not included under the Creative Commons license, users will need to obtain permission from the license holder to reproduce the material. To view a copy of this license, visit http://creativecommons.org/licenses/by/4.0/ 